\title{
O DIREITO CONSTITUCIONAL COMO PROCESSO ${ }^{(1)}$
}

\author{
Alfredo Attié Júnior \\ Mestre pelo Departamento de Filosofia e Teoria Geral do Direito da \\ Faculdade de Direito da Universidade de São Paulo.
}

\begin{abstract}
Resumo: O presente trabalho recupera a narureza histórica e conceitual do Estado como forma de alienação da capacidade política, iniciando uma crítica à Constituição e ao processo como instrumento de efetivação da vontade constitucional, propondo a restauraçăo da questão do fundamento do pensamento político e da sociedade.
\end{abstract}

\begin{abstract}
I. Reconstruction of historical and conceptual nature of the State as a form to alienate political capacity; II. Critical view of constitutional law and procedure as a mean to achieve constitutional will; III. Restoration of political thought and society fundamental.
\end{abstract}

Unitermos: O termo Estado; Soberania; Contrato; Direito Constitucional; Fundamento da Sociedade.

"De ma part je pense bien et ne suis pas trompé puis qu'il n'est rien si contraire a dieu tout libéral et debonnaire que la tirannie, qu'il reserve la bas a part pour les tirans et leurs complices quelque peine particuliere" ${ }^{\text {(3) }}$

I.

A sentença de La Boétie, "Rimbaud do pensamento" (4), lança nosso olhar para um instante que, a toda prova, tornou-se imemorial, ao menos para os teóricos do direito. Não por sua antiguidade criar empecilho para seu alcance pela reminiscência, mas porque obliterado na construção da moderna ciência jurídica.

Trata-se do momento de constituição de uma forma social que, por assumir princípio absolutamente diverso daquele até então reinantes, subverteu a cena política.

Com efeito, os séculos XV, XVI e XVII europeus assistiram à introdução de um elemnto novo na situação de poder. Habermas ${ }^{(5)}$ bem resume o processo: "d'une part la centralisation et du même coup la bureaucratisation du pouvoir, transformant l'appareil étatique du gouvernement des princes, d'autre part l'expansion de la circulation capitaliste des marchandises et un bouleversement progressif du mode de production familial. Car ce nouveau complexe d'interêts dépendant du marché et non plus de la famille qui caractérise les économies nationales et territoriales, se développe tant et si bien sous l'égide d'une autorité accédant à ce moment à la souveraneté qu'on peut concevoir celle-ci, en tant qu'elle jouit dans la societé civile d'un pouvoir pratiquement absolu, selon les catégories de 
l'État moderne, autrement dit d'un droit formel utilisé techniquement pour régler les relations sociales".

Em uma palavra, tal transformação corresponde ao surgimento do Estado, cuja primeira designação como forma de organização política devemos a Machiavelli (6): "tutti stati, tutti e dominii che hanno avuto e hanno imperio sopra li uomini, sono stati e sono o republiche o principati"

O termo Estado (status, em latim, e stato, na língua de Machiavelli) até então, servia para referir uma situação pessoal como as categorias status libertatis, status civitatis e status familiae, a que, até hoje, os juristas estão habituados. E é sintomático que tenha sido esta a palavra escolhida.

No direito romano, status era atributo das personae, quer dizer, dos homens, para os quais se constituíra o direito (7). Isto significa que o termo explicitava uma característica fundamental, atinente aos homens, sublinhemos, válida para as relações da vida pública e da vida privada. Assim, o fato de ser livre, ingênuo, liberto ou escravo; o fato de ser cidadão (cives) ou não (peregrini), ou, no que diz respeito aos libertini, se cives romani, latini iuniani ou dediticii; finalmente o fato de ser personae sui iuris ou alieni iuris. O status, destarte, estabelecia a existência dos homens em face da sociedade romana, ao explicitar sua capacidade jurídica, em sentido amplo, quer dizer, política e privada.

Ao desacoplar o termo das pessoas e transferílo para um "homem artificial" (8), a modernidade engendrou um novo modo de política, em plena correspondência à real expropriação sofrida por aquelas.

Vale a pena, para explicitá-la, discutir algumas lições de duas das principais testemunhas deste evento: Machiavelli e Hobbes.

Não há propriamente uma definição do stato na obra do pensador fiorentino. Mesmo o termo como é de se esperar em abordagens pioneiras - não possui um emprego unívoco (aliás, como todos os termos-chaves, assim virtu, fortuna, etc.), malgrado esta precisão seja procurada pelo autor. O que releva, porém, é a personificação que, desde logo, Machiavelli produz, ao estabelecer o Estado como um domínio que detém e exerce imperio sobre os homens. Percebe-se que esta pessoa, caracteristicamente, ao exercitar o poder de mando sobre as demais, assume integralmente aqueles atributos de capacidade jurídico-política anteriormente ligados a estas. Ela retira das pessoas a capacidade, que antes thes era inerente, de estabelecer o seu próprio destino, de autonomamente governar-se e constituir sua vida política, transformando-a em soberania.

A soberania é uma capacidade jurídico-política exclusiva, que não reconhece outro poder senão o seu próprio. Ou, como especificaria, pouco mais de meio século após, Bodin (9): "o primeiro sinal do príncipe soberano é o poder de legislar a todos, em geral, e a cada um, em particular ... sem o consentimento de maior, igual nem menor do que ele".

Machiavelli ${ }^{(10)}$, contudo, já o antevia com quase perfeita clareza: "e debbesi pigliare questo per una regola generale: che mai o rado ocorre che alcuna republica o regno sia, da principio, ordinato bene, o al tutto di nuovo, fuora degli ordini vecchi, riformato, se non e ordinato da uno? Anzi e necessario che uno solo sia quello che dia il modo, e dalla cui mente dependa qualunque simile ordinazione. Pero, uno prudente ordinatore d'una republica, e che abbia questo animo, di volere giovare 
non a sé ma al bene comune, non alla sua propria sucessione ma alla comune patria, debbe ingegnarsi di avere l'autorità, solo... Conchiudo, come a ordinare una republica à necessario essere solo".

A soberania é, portanto, a primeira tanto lógica quanto cronologicamente qualidade do Estado. No aspecto lógico, porque o Estado a partir dela se define. No aspecto histórico, posto o Estado somente ter advindo no momento em que foram pilhadas as demais pessoas de seu poder de auto-determinação, entregando esta capacidade de estabelecer o que deva ser considerado bem a este ente abstrato personificado.

Nem se diga que tal concepção do Estado é excepcional, referindo-se àquilo que a tradição, desgraçadamente, guardou como sendo "maquiavelismò", isto é, uma justificação engenhosa da tirania. Machiavelli, na literalidade e na correta interpretação de seus textos, bem como pelo seu testemunho biográfico é intenso à tirania e sua teoria é válida para stato, em geral, seja república, seja regno: "intra tutti gli uomini laudati sono $i$ laudatissimi quelli che sono stati capi e ordinatori delle religioni. Apresso, dipoi, quelli che hanno fondato o republiche o regni... Sono per contrario, infami e detestabili gli uomini destruttori delle religioni, dissipatori de'regni $e$ delle republique, inimici delle virtu, delle lettere, e d'ogni altra arte che arrechi utilitd $e$ onore alla umana generazione; come sono gl'impi, $i$ violenti, gl'ignoranti, $i$ dappochi, gli oziosi, $i$ vili. E nessuno sarà mai si pazzo o si saio, si tristo o si buono, che, prepostagli la elezione delle due qualità d'uomini, non laudi quella che à da laudare, $e$ biasimi quella che e da biasimare: nientedimeno, dipoi, quasi tutti, ingannati da un falso bene e da una falsa gloria, si lasciono andare, o voluntariamente o ignorantemente, nei gradi di coloro che meritano piu biasimo che laude; e potendo fare, con perpetuo loro onore, o una republica o uno regno, si volgano alla tirannide: né si avveggono per questo partito quanta fama, quanta gloria, quanto onore, sicurtà, quiete, con sodisfazione d'animo, ei figgono; e in quanta infamia, vituperio, biasimo, pericolo e inquietudine, incorrono" (11). E é um cuidadoso historiador da política que leva mais longe o argumento (12): "what Machiavelli primarily has in mind in laying so much emphasis on liberty is that a city bent on greatness must remain free from all forms of political servitude, whether imposed internally by the rule of a tyrant or externally by an imperial power".

Lembremos, ainda, que mesmo a crítica laboétiana dirige-se contra o princípio do Estado, em geral, e não contra a tirania entendida tecnicamente como forma degenerada da monarquia (13). Assim (14): "il y a trois sortes de tirans, les uns ont le roiaume par election du peuple; les autres par la force des armes; les autres par sucession de leur race... Ainsi pour en dire la verité, je ne voi bien qu'il y a entr'eus quelque différence; mais de chois je ni en vois point, et estant les moiens de venir aus regnes divers, toujours la façon de regner est quasi semblable, les esleus comme s'ils avoient pris des toreaus a domter, ainsi les traictent ils: les conquerans en font comme de leur proie; les successeurs pensent d'en faire ainsi que de leurs naturels esclaves".

Em resumo, o princípio do Estado é um só, o de ocupar o espaço político, expropriando aqueles que até então o habitavam. Este princípio é a soberania.

Hobbes apanhará este processo já em adiantado grau de desenvolvimento, sendo seu estudo, portanto, mais preciso, talvez mais arguto. Com efeito, ao captar o iter de constituição do Estado como um problema nitidamente jurídico, coube ao 
pensador inglês, ao lado de Grotius ${ }^{(15)}$, abrir caminho para a concepção moderna do direito (16).

Pode-se interpretar a cena hobbesiana como a da presença, inicialmente, de uma multiplicidade de entes dotados de plena capacidade de autodeterminar-se. Entes que se definem como vontade de apropriação - signo de sua obsessão pela vida - e cuja garantia da liberdade natural é a força ou arma que cada um possui (a rigor, o corpo natural e qualquer extensão artificial dele).

A natureza, portanto, é um mundo atomizado: indivíduos em constante batalha. $O$ corpo natural somente pode ser individual porque qualquer universalidade é sempre uma abstração da linguagem, um construtor da razão.

É à razão, pois, que cumpre superar este estádio de luta de cada um contra todos, em nome da primeira lei natural: "procurar a paz e seguí-la", e do direito natural: "por todos os meios que pudermos, defendermo-nos a nós mesmos", conjugados na máxima: "que todo homem deve esforçar-se pela paz, na medida em que tenha esperança de conseguí-la, e caso não a consiga pode procurar e usar todas as ajudas e vantagens da guerra" (17).

A razão, ao iniciar a superação desta situação que pode levar à destruição temor hobbesiano -, exige que todos os homens deponham suas armas, renunciando "a seu direito" (observe-se: o direito natural da autonomia da existência), ou, mais precisamente, transferindo-o, o "que se chama contrato", sob a garantia de um "poder comum situado acima dos contratantes, com direito e força suficiente para impor seu cumprimento" (18).

Este contrato, pelo qual todos os homens abrem mão de sua capacidade política, gera o Estado, transformando a multidão de corpos naturais em um córpo artificial imagem, da unidade, representação da união: "a única maneira de instituir um tal poder comum, capaz de defendê-los das invasões dos estrangeiros e das injúrias uns dos outros, garantindo-lhes assim uma segurança suficiente para que, mediante seu próprio labor e graças aos frutos da terra, possam alimentar-se e viver satisfeitos, é conferir toda sua força e poder a um homem, ou a uma assembléia de homens, que possa reduzir suas diversas vontades, por pluralidade de votos, a uma só vontade. O que equivale a dizer: designar um homem ou uma assembléia de homens como representante de suas pessoas ... Isto é mais do que consentimento, ou concórdia, é uma verdadeira unidade de todos eles, numa só e mesma pessoa, realizada por um pacto de cada homem com todos os homens ... Feito isto, à multidão assim unida numa só pessoa chama Estado, em latim civitas. É esta a geração daquele grande leviathan, ou antes - para falar em termos mais reverentes daquele deus mortal, ao qual devemos, abaixo do deus imortal, nossa paz e defesa. Pois graças a esta autoridade que lhe é dada por cada indivíduo no Estado, é-lhe conferido o uso de tamanho poder e força que o terror assim inspirado o torna capaz de conformar a vontade de todos eles ... Aquele que é portador dessa pessoa se chama soberano, e dele se diz que possui poder soberano. Todos os restantes são súditos" (19)

Destarte, o Estado constitui-se na alienação da capacidade política; o Estado é uma forma de expropriação da capacidade política. Uma abstração fantasmagórica para qual se direciona a existência dos homens, substituindo-os no poder de determiná-la. 
Parece que a realidade deste processo, bem como a engenhosidade dos discursos dos coetâneos escaparam aos teóricos modernos do direito, os quais acabam por resumir sua análise política ao Estado, por causa disto, ao falarem deste objeto, seus estudos não passam de descrições estruturais ou funcionais a seu respeito, assim captando-o a-historicamente.

Retiremos, antes de tudo, algumas conseqüências lógicas da presença histórica do Estado na política.

É certo que, ao se considerar o advento do Estado como um valor bom na história da humanidade (caso de Machiavelli e de Hobbes), deve-se imaginar meios ou instrumentos que garantam sua permanência. Estado, lembremos, 6 o particípio do verbo estar, e designa um modo de ser, uma condição, significando algo que se pereniza no tempo e no espaço.

Ora, o primeiro ato de introdução do Estado é um contrato. Este pacto (social e político) nada mais é do que a constituição (em todos os sentidos equívocos que possui a palavra ${ }^{(21)}$ ) do Estado. Admita-se ou não, a idéia de constituição está implícita na idéia de Estado, ela é a forma jurídico-política que garante a existência deste ente, a sua capacidade jurídico-política (soberania) perante as demais pessoas que têm sua existência própria determinada por ele ${ }^{(22)}$.

Primeiro, pois, os direitos exerciveis pela soberania, depois os direitos dos homens ${ }^{(23)}$, ou seja, dos súditos ou sujeitos ${ }^{(24)}$.

Não é à toa, portanto, que a idéia do pacto (ou da constituição, como se pretende neste trabalho) como protetor e defensor dos interesses das pessoas que 0 constituem seja cronologicamente posterior (25).

Cumpriu a Rosseau ${ }^{(26)}$ a compreensão plena da constituição como atributo do soberano (Estado), instrumento da alienação, construção da soberania: "essas cláusulas quando bem compreendidas, reduzem-se todas a uma só: a alienação total de cada associado, com todos os seus direitos, à comunidade toda, porque, em primeiro lugar, cada um dando-se completamente, a condição é igual para todos ... Ademais, fazendo-se a alienação sem reservas, a união é tão perfeita quanto possa ser e a nenhum associado restará algo mais a reclamar, pois, se restassem alguns direitos aos particulares, como não haveria nesse caso um superior comum .. o estado de natureza substituiria, e a associação se tornaria necessariamente tirânica ou vã ... Esse ato de associação produz ... um corpo moral e coletivo ... Ganha sua unidade, seu eu comum, sua vida e sua vontade. Essa pessoa pública, que se forma, desse modo, pela união de todas as outras, tomava antigamente o nome de cité e, hoje, o de república ou de corpo político, o qual é chamado por seus membros de Estado quando passivo, soberano quando ativo, e potência quando comparado a seus semelhantes. Quanto aos associados, recebem, coletivamente, o nome de povo e se chamam, em particular, citoyens, enquanto partícipes da autoridade soberana, e súditos/sujets/ enquanto submetidos às leis do Estado. Esses termos, no entanto, confundem-se freqüentemente e são usados indistintamente".

Sem desejarmos, contudo, assumir plenamente a tese nominalista $(27)$, ao compreendermos o Estado como realidade abstrata, devemos entender a constituição como sua objetivação: o Estado, pessoa, corpo político, homem artificial, torna-se realidade objetiva perante seus entes constituintes (entes políticos) e agora súditos (entes a-políticos) ao se explicitar na Carta que, em 
princípio, é suma do pacto de sua instituição e, depois, articulação dos direitos dos submetidos à autoridade estatal - somente admissíveis na medida em que coerentes com esta autoridade, quando não a contrariem ou ponham em risco.

O direito constitucional ${ }^{(28)}$ nasce com a vocação (e por isto se torna) a ritualização da soberania. Destarte, em cada uma das formas em que se estabelece o ordenamento jurídico - seja seu momento ficticiamente primevo, a assembléia, manifestação do poder constituinte, seja nas eleições gerais, no exercício do poder constituído, etc. - está-se a comemorar a fundação do Estado e a se repetir ritualmente o pacto, a constituição original.

II.

Devemos, agora, voltar um pouco nossa anạlise à realidade constitucional atual brasileira.

Antes, é bom salientarmos que, ao empreendermos a recuperação para a memória jurídica destas questões, pretendemos não-somente mostrar como a política e o direito não se resumem historicamente ao Estado, mas abrir caminho para um diálogo com a escola das "novas tendências do direito processual" ou da "instrumentalidade do processo", a partir de um tema concreto, como adiante se verá.

Se abrirmos a atual Constituição iremos. notar que, em todas as questões que analisemos, ela nada possui de inovação; pelo contrário, deixa bem clara a objetivação da soberania e a ritualização da fundação do Estado.

O "preâmbulo", por exemplo, o diz expressamente, corroborando a mistificação da reunião do povo para a criação do Estado: "Nós, representantes do povo brasileiro, reunidos em Assembléia Nacional Constituinte para instituir um Estado Democrático..."

Há aqui já três níveis de representação (29): o povo (lembremos, representação coletiva dos corpos naturais), seus representantes portadores da vontade nacional e a vontade geral (que se estabelece como nação, em Siéyes, -única legítima para constituir o pacto ${ }^{(30)}$, mas que em Rousseau já encontra um nível elevado de separação em relação aos homens, corpos individuais (31), sobretudo pelo que se vê da diferença entre a "vontade de todos" e a "vontade geral" $^{(32)}$ ).

Quando se fixam, a seguir, no "título I", os "fundamentos" da "República Federativa do Brasil", o primeiro, evidentemente, é a soberania, o que demonstra a institucionalização plena da perda da capacidade política pelos homens desde antes iniciada, quando ábdicarem do poder de decidir por si sua constituição e escolheram representantes.

A partir deste ponto, portanto, estes homens deixam de se representar em seus corpos naturais e passam a ser nominados em sua relação com o ente dotado de capacidade política exclusivamente: cidadãos. O segundo "fundamento" do Estado, com efeito, é a "cidadania", ou a qualidade de ser membro do soberano, de ser súdito. 
Feito isto, os membros aceitos da sociedade política - que, a partir de agora, é o Estado - passam a receber a parte que lhes cabe, segundo a Constituição, aos seus "direitos", os quais, na verdade, também são abstrações filosoficamente referiveis à modernidade: "dignidade da pessoa humana", valores sociais do trabalho e da livre iniciativa".

E o "pluralismo político", com certeza, não chega a abranger a possibilidade de restaurar a capacidade política dos entes expropriados, sendo um pluralismo - se é que o há que se unifica no Estado (33). poder!

Este é, portanto, o direito material! Esta a situação política e as relações de

Diante deste quadro, que pretende a escola das "novas tendências", da "instrumentalidade do processo"?

Antes de tudo, o que acredita ser original talvez não o seja senão no círculo muito restrito dos próprios processualistas. Em realidade, o que seus teóricos produzem ${ }^{(34)}$, ao fixarem o processo como instrumento, é a legitimação do Estado também pelo procedimento de efetivação de sua vontade.

Veja-se, neste sentido, o testemunho de um importante sociólogo contemporâneo, apólogo da dominação (35): "tal como a categoria do contrato para o âmbito da sociedade, assim a categoria do procedimento para o âmbito do Estado parece apresentar aquela fórmula mágica que combina a mais alta medida de segurança e liberdade que se pode praticar concretamente no dia-a-dia e que transmite, enquanto instituição, todas as resoluções do futuro...".

Destarte, mesmo que os autores pretendam o estabelecimento de uma dialógica no interior do procedimento, que o torne, por assim dizer, democrático exercício da participação e controle do poder , as escolhas dos caminhos já foram feitas de antemão: o processo realiza o objetivo do Estado ${ }^{(36)}$.

Ora, tal vontade estatal é dada, em primeiro lugar, na Constituição (37): "todo o direito processual, como ramo do direito público, tem suas linhas fundamentais traçadas pelo direito constitucional, que fixa a estrutura dos órgãos jurisdicionais, que garante a distribuição da justiça e a declaração do direito objetivo, que estabelece alguns princípios processuais ... Mas além de seus pressupostos constitucionais, comuns a todos os ramos do direito, o direito processual é fundamentalmente determinado pela Constituição em muitos de seus aspectos e institutos característicos. Alguns dos princípios gerais que o informam são, ao menos inicialmente, princípios constitucionais ou seus corolários: em virtude deles o processo apresenta certos aspectos ... Isso significa, em última análise, que o processo não é apenas instrumento técnico, mas sobretudo ético ... Mas é justamente a Constituição, como resultado do equilíbrio das forças políticas existentes na sociedade ém dado momento histórico, que se constitui no instrumento jurídico de que se deve utilizar o processualista para o completo entendimento do fenômeno processo e de seus princípios".

Quando se retira a perspectiva do poder e se a estabelece sobre a "realização dos direitos", no sentido de ter o processo plena "aderência à realidade sócio-jurídica a que se destina" ${ }^{(38)}$, nada se modifica, pois esses direitos, como fizemos observar, não existem senão secundariamente em relação à soberania, e, 
afinal, as "garantias" (39) constitucionais dirige,-se, sobretudo, à jurisdição, isto é, ao poder do Estado de dizer o direito.

Desta perspectiva, o controle de constitucionalidade das leis não passará de uma astúcia estatal para controlar a pluralidade de vontades e adequá-las à sua única manifestação legítima. Demonstra tal assertiva o fato de que "hoje quase todas as constituições modernas do mundo ocidental tendem, já, a afirmar o seu caráter de constituições rígidas e não mais flexíveis ... De resto, também todas as constituições da Europa Oriental têm caráter rígido" (40).

Os constitucionalistas bem definem a função do controle: "é uma mecânica voltada a policiar a ordem jurídica, que tem necessidade de expelir de seu seio tudo aquilo que lhe contradite" ${ }^{(41)}$, ou é "a verificação da adequação de um ato jurídico (particularmente da lei) à Constituição" (42).

Observe-se que subjaz a tais conceitos um paradoxo bastante elucidativo. Os autores, em geral, costumam estabelecer a Constituição como fundamento da ordem jurídica, afirmando que está acima das demais vontades. Entretanto, nada do que é fundamento (base, fundo) pode estar sobre o que alicerça. Confusão sintomática de incorreta análise de sua fonte, a tradição kantiana, por intermédio de Kelsen (43).

A origem da grundnorm é kantiana (44), pelo que se extrai da seguinte passagem da introdução à metafísica dos costumes, de 1797: "as leis vinculantes, para as quais é possível uma legislação externa, chamam-se, em geral, leis externas (leges externae). Aquelas, dentre estas, cuja vinculatoriedade possa ser conhecida $a$ priori pela razão, mesmo que sem legislação externa, denominam-se leis externas naturais; aquelas, ao contrário, que não vinculam sem uma legislação externa real, ou seja, que sem esta última não seriam leis, chamam-se leis positivas. É, pois, possível pensar uma legislação externa contendo só leis positivas. Neste caso, porém, deveria precedê-la uma lei natural a fundamentar a autoridade do legislador, quer dizer, sua faculdade de vincular outros por seu mero arbítrio".

A partir deste iluminado axioma, erige-se a teoria kelsiana, onde a grundnorm ${ }^{45}$ é a resposta "epistemológica" ou "teorético-gnoseológica" à indagação sobre a razão de validade de uma ordem jurídica (46) contendo só leis positivas.

A grundnorm, é importante esclarecer, não é fundamento, não está colocada acima da ordem jurídica dada, nem lhe é anterior. Ela é apenas seu pressuposto, bem assim, lógico ${ }^{(47)}$.

A grundnorm, portanto, é quase que tautológica: "é este o caso se a pessoa a cujas ordens devemos obedecer por força da norma agora em questão é considerada como a autoridade mais alta" (48).

Para o caso da Constituição, pois, a norma-razão de ser obedecida está em que o Estado assim o determina e o Estado é o detentor da soberania, única e exclusiva fonte de poder, como fixa a própria Constituição. $\mathrm{O}$ argumento beiraria o absurdo, se não fosse corroborado pelo próprio jurista austríaco ${ }^{(49)}$. Destarte, concluímos, deve-se obedecer à Constituição porque há uma norma-razão que a obriga; e a obrigatoriedade do comando da norma-razão possui seu motivo na Constituição.

O paradoxo não possui solução nos limites da teoria moderna do direito, sempre esquecida de sua origem. Ele só encontra justificação se entendemos bem o surgimento do Estado e a função da Constituição. Há algo que obriga à obediência à 
Carta do Estado, que não é a grundnorm kelseniana, mas é a essência do próprio Estado e a relação fundada - de temor - entre ele e seus súditos ${ }^{(50)}$.

Enfim, toda esta teoria da instrumentalidade esbarra numa tautologia: o que institucionaliza a violência do Estado é a Constituição; se o processo apenas instrumentaliza a Constituição (vontade do soberano), ele tão-somente serve como um meio a mais de afirmação da denominação fundante da modernidade.

\section{III.}

A indagação que resta é a seguinte: estariam os súditos sempre presos às artimanhas deste círculo vicioso da sujeição?

A resposta, para se mostrar negativa, exige um esforço de superação dos limites teóricos impostos pela ciência jurídica moderna.

Devemos recuperar para o direito a noção de fundamento, em particular de fundamento da sociedade política, isto na medida em que não se confunda com a procura da razão da dominação ${ }^{(51)}$.

O fundamento não é um dever-ser, sob pena de retornarmos à tautologia da manifestação do poder (soberano). O fundamento é aquilo que se faz com que o ente seja como é, quase, destarte, confundindo-se com o próprio ser do ente, no caso, da sociedade dita política.

Um importante pensador alemão, crítico e, de certo modo, superador do kantismo, já alertava que o desejo de "dar a um povo a priori uma constituição $a$ priori, até quando ela seja em seu conteúdo mais ou menos racional, é uma fantasia que não tem em conta o elemento que faz dela mais do que um ser de razão. Cada povo tem, por conseguinte, a constituição que lhe convém e se lhe adequa" ${ }^{(52)}$. Ao fazê-lo, chama nossa atenção para a diferença entre uma Constituição dada a priori e uma oriunda do próprio modus vivendi de uma sociedade.

Sem desejarmos voltar à análise da própria questão do fundamento (53), basta-nos, aqui, observar que a distinção entre fundamento da vida social (54) è razão da dominação social é de suma importância para a percepção de que nenhuma teoria que busque restabelecer a situação anterior de politização dos homens, pode deixar de trabalhar com a categoria do fundamento.

$R e$-politizar este ente que é o homem significa restaurar sua existência, pois o ser do homem é o ser com os outros, sua presença no mundo é co-existência ${ }^{(55)}$.

Se se quiser, o homem é o animal político ${ }^{(56)}$.

Politizar o homem não é fazê-lo "participar" da sociedade inaugurada pelo Estado, pois o Estado é a negação do social, ao estabelecer os homens como entes isolados, e é a subversão da política, ao efetuar sua re-união, pelo pacto constituinte, como sujeitos.

Para tanto é preciso trabalhar com o direito não exclusivamente ao nível da razão da dominação (a constituição), mas também ao nível do fundamento da política, recuperando para o homem o espaço da política de que foi expropriado.

Esta tarefa é urgente e é fundamental que não falhemos, pois a lamentação da derrota é pura dor, o arrependimento por não haver coragem para lutar é puro sofrimento, como bem expressou o poeta: "sou homem, depois desse falimento? Sou o que não foi, o que vai ficar calado. Sei que agora é tarde, e temo abreviar com a 
vida, nos rasos do mundo. Mas, então, ao menos, que, no artigo da morte, peguem em mim, e me depositem também numa canoinha de nada, nessa água que não pára, de longas beiras: e, eu, rio abaixo, rio a fora, rio a dentro - o rio".

Que no rio da existência não haja mais lugar para a desumanidade!

\section{Notas}

1. Trabalho apresentado à Escola Paulista da Magistratura, ao término do curso "Processo Civil na Nova Constituição", coordenado pelo Professor Doutor Kazuo Watanabe. Respeitosamente dedicado ao Professor Doutor Fábio Konder Comparato, exemplo da liberdade de pensamento e manifestação do jurista, tão rara nestes tempos obscuros. Outono de 1990.

2. Juiz de Direito em São Paulo. Mestre em Filosofia e Teoria Geral do Direito pela Universidade de São Paulo. Docente dos Departamentos de Filosofia e Teoria Geral do Direito da FDUSP e Direito da UNESP. Membro de Comitê de Filosofia do Direito da Associação Interamericana de Advogados. Ex-Procurador do Estado de São Paulo.

3. LA BOÉTIE, E. de Le discours de la servitude volontaire, c. 1548.

4. CLASTRES, P. Liberdade, mau encontro, inominável, 1976.

5. HABERMAS, J. Théorie et pratique. (trad. franc.) Paris. vol I

6. De principatibus, c. 1513.

7. Hominum causa omne ius constitutum est (Hermoginianus in digesto. $1,5,2)$.

8. HOBBES, T. Leviathan, 1651

9. BODIN, J. Les six livres de la Republique, 1576.

10. Discorsi sopra la prima deca di Tito Livio, c. 1519.

11. Idem, ibidem.

12. SKINNER, Q. Machiavelli, 1981.

13. ARISTÓTELES. Política, séc. III a.c.

14. LA BOÉTIE, E. op. cit.

15. Este em seu Direito da guerra e da paz, 1625. 
16. ATTIÉ Junior, A. Sobre a alteridade: para uma crítica da antropologia do direito. São Paulo, 1989.

17. HOBBES, T. op. cit.

18. Idem, ibidem.

19. Idem, ibidem.

20. RUFFIA, P. B. de. Derecho Constitucional. (trad. espanhola) Madrid, 2. ed.: "status, orden, conformación, estructura esencial de un ente o de un organismo en general"; "todo aquel complejo de normas jurídicas fundamentales, escritas o no escritas, capaz de trazar les líneas maestras del mismo ordenamiento"; "un complejo de normas legislativas que se distinguen de las ordinárias por su más arduo y solmne proceso formativo"; "acto fundamental en el cual han sido formuladas solemnemente la gran mayoría de las normas materialmente constitucionales"; "aquel complejo de instituciones jurídicas, positivamente válidas y operantes, que realizan un fin político que es el resultado de los diversos fines perseguidos por las distintas fuerzas políticas activas en lucha entre sí, en un país determinado y un momento histórico dado".

21. "Diz-se que um Estado foi instituído quando uma multidão de homens concordam e pactuam, cada um com cada um dos outros, que a qualquer homem ou assembléia de homens a quem seja atribuído pela maioria o direito de representar a pessoa de todos eles (ou seja, de ser representante); todos sem exceção, tanto os que votaram a favor dele quanto os que votaram contra ele, deverão autorizar todos os atos e decisões desse homem ou assembléia de homens" (HOBBES. op. cit.).

22. "É desta instituição do Estado que derivam todos os direitos e faculdades daquele ou daqueles a quem o poder soberano é conferido mediante o consentimento do povo reunido... Pertence à soberania todo o poder de prescrever as regras através das quais todo homem pode saber quais os bens de que pode gozar, e quais as ações que pode praticar, sem ser molestado por qualquer de seus concidadãos... Pertence ao poder soberano a autoridade judicial, quer dizer, o direito de ouvir e julgar todas as controvérsias que possam surgir com respeito às leis, tanto civis quanto naturais, ou com respeito aos fatos... Pertence à soberania o direito de fazer a guerra e a paz com outras nações e Estados... É confiado ao soberano o direito de recompensar com riquezas e honras, e o de punir com castigos corporais ou pecuniários, ou com a ignomínia, a qualquer súdito, de acordo com a lei que previamente estabeleceu... de acordo com o que considerar mais capaz de conduzir ao serviço do Estado" (Idem, ibidem). 
23. "São estes os direitos que constituem a essência da soberania, e são as marcas pelas quais se pode distinguir em que homem, ou assembléia de homens, se localiza e reside o poder soberano... Tudo isto torna necessário que existam leis de honra, e que seja atribuído um valor aos homens que bem serviram, ou que sejam capazes de bem servir ao Estado" (idem, ibidem).

24. Muito sintomaticamente, a palavra francesa que diz șujeito, diz também súdito: sujet ( $v$., por exemplo, a seguir, em Rousseau). Aliás, o termo subiectus designa exatamente o que está submetido a algo ou a alguém.

25. ROUSSEAU, J.J. Do contrato social, 1762 : "Encontrar uma forma de associação que defenda e proteja a pessoa e os bens de cada associado com toda a força comum, e pela qual cada um, unindo-se a todos, só obedece contudo a si mesmo, permanecendo, assim, tão livre quanto antes. Esse, o problema fundamental cuja solução o contrato social oferece".

26. Op. cit.

27. A que Hobbes se vinculou e que Rousseau combateu.

28. Somente no decorrer do século XVIII, por assim dizer, positivado.

29. Sobre a representação, V. ATTIÉ Junior, A. Sobre a alteridade cit.: a representação é um conceito ligado ao advento da modernidade, "os gregos não possuíam palavra para significá-lo e o verbo repraesentare, entre os romanos não assumia o conteúdo que hoje the fornecemos", possuindo o sentido apenas de estar presente, fazer-se presente. "Na Idade Moderna, as instituiçōes passaram a ser representativas por essência". Representar é, modernamente, "fazer-se presente em nome de algo ou alguém, reproduzí-lo, simbolizá-lo e, também, encenar, dissimular, encobrir alguma coisa, mostrando-a ser de forma diversa do que é verdade. Pela representação, pois, arte e vida se reconciliam..."

30. Qu'est-ce que le tiers état? 1789 : "a nação existe antes de tudo, é a origem de tudo".

31. "Desde o momento em que essa multidão se encontre assim reunida em um corpo, não se pode ofender um dos membros sem atacar o corpo, sem, ainda, ofender o corpo sem que os membros se ressintam" (Do contrato social cit.).

32. Idem, ibidem : "Há comumente muita diferença entre a vontade de todos e a vontade geral. Esta se prende somente ao interesse comum; a outra, ao interesse privado e não passa de uma soma das vontades particulares". 
33. Observe-se que tudo se faz segundo a representação, somente sendo conferida a participação "nos termos desta Constituição". Note-se, ainda, a recusa peremptória da admissão da pluralidade de nações no território "nacional brasileiro". E, afinal, que o Estado se forma pela "união indissolúvel dos Estados, dos Municípios e do Distrito Federal" e não dos homens que o compõem...

34. Com toda a sinceridade intelectual e o cuidado somente encontrado entre os juristas de escola, é preciso assegurar, para que se entenda que a crítica aqui levada a cabo tão-somente leva a sério as idéias da escola ao discutí-las.

35. LUHMANN, N. Legitimação pelo procedimento, 1969. Ainda: "o poder é também um mecanismo de transmissão de resultados de seleção e até mesmo de obras de seleção produzidas pela decisão. Quem tem o poder pode motivar outros a adotar as suas decisões como premissas de procedimento, portanto a aceitar como compulsiva uma seleção dentro do âmbito de possíveis alternativas de comportamento ... Tem-se de partir da hipótese de que no procedimento se criem essas razões adicionais para aprovação das decisões e de que, neste sentido, o poder gere a decisão e a torne legítima, isto é, que se torne independente, pelo imperativo exercido concretamente. Visto desta forma, o objetivo do procedimento juridicamente organizado consiste em tornar intersubjetivamente transmissível a redução de complexidade que com a ajuda da verdade, quer através da criação do poder legítimo de decisão ... Esta força de redução da complexidade é essencialmente desempenhada pela criação de estruturas, isto é, pela generalização das expectativas de comportamento que, depois, durante largos períodos de tempo, são válidos transitória e objetivamente para diversas situações e são válidos socialmente para uma maioria ... A estrutura de um sistema de procedimento é, primeiramente, delineada por normas jurídicas gerais, válidas para diversos procedimentos. Estas normas não constituem, porém, o procedimento propriamente dito e uma justificação por recurso a elas não constitui a legalidade pelo procedimento. Contudo, elas reduzem a tal ponto o número ilimitado de formas possíveis de comportamento, que se torna possível, sem incômodas discussões prévias sobre o sentido e finalidade de uma reunião, por procedimentos individuais em movimento como sistema, definir a sua temática e os seus limites e tornar os participantes conscientes disso. Como sistemas corretos de ação, esses procedimentos então ocupam um lugar único no espaço e no tempo. Adquirem, assim, uma perspectiva que lhes é peculiar quanto ao seu ambiente e quanto ao seu próprio significado, manifestando-se numa conjuntura especial de acontecimento, símbolos e representações e reconhecendo-se, como regra geral, com rapidez ... A vantagem da estrutura e definição dos limites concretamente reconhecidos do sistema não constituem as únicas formas de redução, nem as mais importantes para o nosso problema. Os procedimentos pressupõem sempre uma organização básica, sendo possíveis só como sistemas parciais de um sistema maior, que lhes sobrevive, que os representa e que lhes mantém determinadas regras de comportamento ... Por meio de regras de irrelevância, por meio de regras de admissão, aprovação de pessoas e introdução de temas, por meio de regras de tradução e definição daquilo que perturba ou até destrói o sistema e daquilo que se pode fazer para o evitar, 
circunscreve-se o processo e se leva o mesmo a despertar para uma certa autonomia até que a decisão seja emitida. À medida que o processo se desenrola, reduzem-se as possibilidades de atuação dos participantes. Cada um tem que tomar em consideração aquilo que já disse, ou se absteve de dizer. As declarações comprometem. As oportunidades desperdiçadas não voltam mais. Os protestos atrasados não são dignos de crédito ... Os participantes cooperam na determinação da história do processo jurídico ... Não se decide, previamente, entre cooperação e conflito através da estrutura do sistema. Ela permite ambos. Por isso não tem de se esclarecer, em cada caso, qual a função que domina nas comunicações isoladas de processo jurídico. Daí os procedimentos, tipicamente, fundirem ambas as funções. Isso permite resolver conflitos sob a ideologia de uma procura coletiva da verdade, opinião que conseguiu enganar a concepção clássica de processo jurídico. Assim se regularizam os conflitos, isto é, se fortalecem através de certas condições secundárias de interpretação do processo" e passim.

36. DINAMARCO, C. R. A instrumentalidade do processo. 1987: "Mediante a utilização do sistema processual, propōe-se o Estado, antes de tudo, a realizar objetivos que são seus.

Quer se pense na pacificação social, educação para o exercício e respeito a direitos, ou na manutenção da autoridade do ordenamento jurídico-substancial e da sua própria, nas garantias à liberdade, na oferta de meios de participação democrática, ou mesmo no objetivo jurídico-instrumental de atuar a vontade da lei (e tais são os escopos da ordem processual) - sempre é algo ligado ao interesse público que prepondera na justificação da própria existência da ordem processual e dos institutos, princípios e normas que a integram. Preestabelecidos os fins do Estado, ele não dispensa o poder para caminhar na direção deles; e, precisando exercer o poder, precisa também o Estado-de-direito estabelecer as regras pertinentes, seja para endereçar com isso a conduta dos seus numerosos agentes (no caso, os juízes), seja para ditar condições limites e formas do exercício do poder. Em torno deste, portanto (no caso, em torno da jurisdição) é que gravitam os demais institutos do direito processual e sua disciplina ... Não obstante se diga teoria geral do processo e se continue sempre a dizer direito processual, tem-se no fundo e essencialmente a disciplina do poder e do seu exercício e esse é o fator de unidade que reúne numa teoria os institutos, fenômenos, princípios e normas de diversos ramos aparentemente distintos e independentes entre si ... A preponderância metodológica da jurisdição, ao contrário do que se passa com a preferência pela ação ou pelo processo, corresponde à preconizada visão publicista do sistema, como instrumento do Estado, que ele usa para o cumprimento de objetivos seus ...

O significado político do processo como sistema aberto, voltado à preservação dos valores postos pela sociedade e afirmados pelo Estado, exige que ele seja examinado também a partir de uma perspectiva externa; exige uma tomada de consciência desse universo axiológico a tutelar e da maneira como o próprio Estado define a sua função e atitude perante tais valores ... A idéia de poder, que está ao centro da visão moderna do direito processual, constitui assim fator de aproximação do processo à política, entendida esta como o processo de escolhas axiológicas e fixação dos destinos do Estado. Compete à política a 'tomada de 
decisões através dos meios públicos; ou seja, decisões que se tomam mediante a linguagem adequada e escoam e se transmitem pelos canais oficiais predispostos na ordem estatal, destinando-se à organização social e determinação das condutas compatíveis como estilo de vida superiormente escolhido ... As decisões que em seu conjunto representam a política partem do número restrito dos sujeitos encarregados delas no seio do Estado e destinam-se a todo o universo dos membros da população ...

Nessa perspectiva, o Estado, que é o mais importante de todos os pólos de poder, aparece até como fonte de poder, em benefício de pessoas que de algum modo logram 'fazer valer suas decisões com a ajuda do Estado' ... Embora ao Estado não caiba o exercício do poder nacional em todas as áreas, nem valer-se de todas as fontes de poder, certo é que ele detém o comando global de todas as manifestações deste, justamente em razão da soberania, que o põe a montante de todos os demais pólos de poder ... Em todos os setores de suas atividades, exercendo diretamente ou comandando o exercício do poder nacional, o Estado decide ... O poder político é, realmente, a capacidade de decidir imperativamente e impor decisões ... Por isto é que o Estado moderno, não renunciando à incontratável supremacia exercida no plano interno, reserva-se a última palavra sobre os assuntos entre particulares e igualmente entre estes e as entidades intermediárias ... e veda qualquer atividade coercitiva que não seja a sua ... O exercício da jurisdição e a sua promessa solene têm, portanto, esse expressivo significado político de enérgica afirmação da soberania ...

Expressão do poder, a jurisdição é canalizada à realização dos fins do próprio Estado e, em face das cambiantes diretrizes políticas que a História exibe, os objetivos que animam consideram-se também sujeitos a essas mesmas variações, no espaço e no tempo" e passim.

37. CINTRA, A.C.A.; GRINOVER, A.P.; DINAMARCO, C.R. Teoria Geral do Processo. Empreguei, aqui, a cópia fornecida da última edição, no prelo, distribuída pela Escola Paulista da Magistratura.

38. GRINOVER, A.P. As garantias constitucionais do processo nas açōes coletivas. (1987) in Novas tendências do Direito Processual, 1990.

39. GRINOVER, A.P. op. cit. e, na mesma coletânea, Defesa, contraditório, igualdade e par condicio na óptica do processo de estrutura cooperatória, 1986.

40. CAPPELLETTI, M. O controle judicial de constitucionalidade das leis no direito comparado. (trad. bras.) 1984 - o original é de 1978.

41. BASTOS, C. Curso de Direito Constitucional, 1989.

42. FERREIRA Filho, M.G. Curso de Direito Constitucional, 1989.

43. Teoria Pura do Direito. 2. ed, 1962. 
44. ATTIE Junior, A. Sobre a alteridade cit. : "A origem da norma fundamental $\ell$, como se viu, kantiana e lança raízes no jusnaturalismo moderno, para o qual o direito natural tem sua fonte na razão (ratio), sendo de maneira absoluta e inafastável, imutável, não sujeito a tempo ou espaço".

45. A rigor, norma-racional ou norma-razão, pois o termo Grund, permitindo ambas as significações, esta se mostra mais pertinente.

46. "Sob a condição de pressupormos a Grundnorm: devemos conduzir-nos como a Constituição prescreve, quer dizer, de harmonia com o sentido subjetivo do ato de vontade constituinte, de harmonia com as prescrições do autor da Constituição. A função desta Grundnorm é tornar racional a validade objetiva de uma ordem jurídica positiva, isto é, das normas, postas através de atos de vontade humanas, de uma ordem coercitiva globalmente eficaz, quer dizer, interpretar o sentido subjetivo destes atos como seu sentido objetivo" (op. cit.).

47. A razão da validade de uma norma positiva (isto é, estabelecida através de um ato de vontade) que prescreve uma determinada conduta, realiza-se por meio de um processo silogístico. Neste silogismo, a premissa maior é uma norma considerada como objetivamente válida (melhor, a afirmação de uma tal norma), por força da qual devemos obedecer aos comandos de uma determinada pessoa, quer dizer, nos devemos conduzir de harmonia com o sentido subjetivo destes atos de comando; a premissa menor é a afirmação do fato de que essa pessoa ordenou que nos devemos conduzir de determinada maneira; e a conclusão, a afirmação da validade da norma ...

A norma afirmada como objetivamente válida na premissa maior, que opera a fundamentação, é uma Grundnorm se a sua validade objetiva já não pode ser posta em questão. Ela já não é mais posta em questão se a sua validade não pode ser fundamentada num processo silogístico. E não pode ser por essa forma fundamentada se a afirmação do fato de que esta norma foi posta pelo ato de vontade de uma pessoa já não é possível como premissa menor de um silogismo ... Quer isto dizer: é pressuposta como Grundnorm (op. cit).

48. Op. cit.

49. KELSEN, H. op. cit.: a Grundnorm refere-se "imediatamente a uma Constituição determinada, efetivamente estabelecida, produzida através do costume ou da elaboração de um estatuto, eficaz em termos globais, enquanto fundamentalmente a validade da mesma Constituição e a ordem coercitiva de acordo com ela criada ... Somente quando pressupomos esta Grundnorm referida a uma Constituição inteiramente determinada, quer dizer, somente quando pressupormos que nos devemos conduzir de acordo com esta Constituição concretamente determinada, é que podemos interpretar o sentido subjetivo do ato constituinte e dos atos constitucionalmente postos como sendo o seu sentido objetivo, quer dizer, como normas jurídicas objetivamente válidas, e as relações constituídas através destas normas como relações jurídicas". 
50. Que teóricos de cosmovisão diversa captaram de modo até satisfatório: MARX, K. O Capital, 1867 : "violência organizada e concentrada da sociedade" ; WEBER, M. A política como vocação, 1918 : "O Estado é uma comunidade humana que pretende, com êxito, o monopólio do uso legítimo da força física dentro de um determinado território ... O Estado é considerado como a única fonte do direito de usar a violência".

51. Erro, afinal, de Ferdinand Lassalle em seu deveras citado opúsculo sobre a Constituição : "a idéia de fundamento traz, implicitamente, a noção de uma necessidade ativa, de uma força eficaz que torna, por lei da necessidade, que o que sobre ela se baseia seja assim e não de outro modo". Quer dizer, o fundamento se resolve no poder, ou, como quer o teórico superficial, "os fatores reais de poder" dos quais a Constituição de um país é a "soma".

52. HEGEL, F. Principios de Filosofia do Direito, 1820.

53. ATTIE Junior, A. Entre o direito e o não direito, 1990.

54. E, portanto, política, daí, dizendo sociedade, também dizemos política.

55. HEIDEGGER, M. Da essência do fundamento. 1928: "E assim o homem, enquanto transcendência existente sobrepujante de possibilidades, é um ser de lonjura. Só mediante distâncias primordiais, que na sua transcendência ele para si estabelece em relação a todo ente, é que nele floresce a verdadeira proximidade às coisas. E somente o poder-ouvir na lonjura é que amadurece para o estar-aí enquanto si-mesmo o despertar da resposta da co-existência, no ser-com, com o qual pode sacrificar a egoidade a fim de se conquistar como autêntico si-mesmo".

56. ARISTÓTELES. op. cit.

São Paulo, 16 de maio de 1990. 